service increment still seems to be linked to beds as the unit of currency for medical training. The links between London's health services, medical education, and research implied in the title of Sir Bernard Tomlinson's report ${ }^{1}$ are not being systematically reshaped across the city.

Secondly, the potential role of community health services trusts in providing an infrastructure based in the community to support learning and teaching is not well understood by the medical schools. Although talk of students being taught in the community is ubiquitous, this is understood primarily in terms of more teaching in general practice. This misses the additional and important opportunities within community health services trusts for students to learn about specialisms based in the community and innovations on the boundary between primary and secondary care-for example, hospital at home-and to experience many forms of multidisciplinary practice.

The community health services trusts offer a range of services that provide opportunities for both teaching and research. We believe that medical educators need to become more knowledgeable about the potential in these trusts and to form new alliances if appropriate training is to be provided for doctors of the 21 st century.

DIANE PLAMPING

City and East London Family and Community Health Services, London E13 8H]

ANGELA TOWLE

King's Fund Centre,

London NW1 7NF

1 Tomlinson B. Report of the inquiry into London's health service, medical education and research. London: HMSO, 1992.

\section{Equity in health care}

\section{Health needs vary among elderly people}

EDrToR,-Allocating resources according to the health needs of the population remains one of the central values of the NHS.' Ken Judge and Nicholas Mays have reviewed some of the weaknesses associated with the current method of allocation but do not fully explain the fundamental flaw in the use of the age-cost curve. ${ }^{2}$ The reason for using an age factor is that elderly people are widely believed to have greater health needs than younger people, and the underlying assumption is that all elderly people have the same health needs.

To test this hypothesis we examined the relation between the proportion of elderly people (aged over 65 ) in the population and the proportion of pensioners who were aged over 75 and living alone for the 28 districts in South Thames region, using 1991 census data. Our analysis showed a highly significant inverse relation between the variables (correlation coefficient $r=-0.49$, $r^{2}=0.24, P=0.009$ ). The figure shows a linear regression line with $95 \%$ confidence intervals. This indicates that small elderly populations have

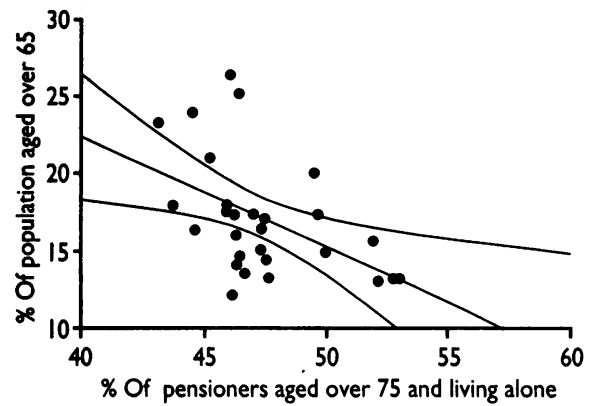

Relation between proportion of elderly people in population and proportion of pensioners aged over 75 and living alone in 28 districts in South Thames region, 1991 (source: common dataset) greater health needs than larger ones. We have previously shown that districts with a high proportion of elderly people tend to have low mortality ratios standardised for age $^{3}$ and low levels of deprivation.

The main factor causing a district's population to contain a high proportion of elderly people is selective migration at retirement, when more affluent people tend to move to coastal areas. In South Thames, for example, over $24 \%$ of the populations of the coastal districts of Worthing, Hastings, and Eastbourne are aged 65 and over, compared with around $14 \%$ of the populations of the inner city boroughs Wandsworth, Camberwell, and Lambeth. Selective migration means that the districts to which people migrate are likely to have a healthier and more affluent elderly population than the districts from which people migrate. The effect of the age-cost curve in the national resource allocation model is to move a disproportionately large share of the resources with elderly people when they migrate, from deprived to affluent areas. Thus distributing a large proportion of the cake according to age without distinguishing between poor elderly and rich elderly people discriminates against the group that has the greatest need.

ES WILLIAMS Director of public health C M SCOTT

Department of Public Health Medicine, ealth services resea

Croydon Health,

Croydon

Surrey CR9 2RH

1 Resource Allocation Working Party. Sharing resources for health in England. London: HMSO, 1976.

2 Judge K, Mays N. Equity in the NHS: allocating resources for health and social care in England. BMf 1994;308: 1363-6. (21 May.)

3 Williams ES, Scott C, Brazil R. NHS distribution of funds unfair. $B M \mathcal{F}^{\mathcal{1}}$ 1992;304:643.

4 Williams ES, Scott C, Brazil R. Resource allocation. BMf 1993;306:1415.

People with chronic disability are marginalised

Edror,-Linda Challis and Melanie Henwood's critique of community care shows clearly the new inequities and perverse incentives created by the 1990 NHS and Community Care Act. ${ }^{1}$ As one of many people who called for proper care needs assessment ${ }^{2}$ and the adoption of a social model of care and support for people with chronic disability, ${ }^{3}$ I am dismayed to see our rhetoric hijacked as a smokescreen for the disenfranchisement of such people from the free care they had under the NHS. We have already seen a huge erosion of continuing care beds in the NHS, even for the most difficult cases of dementia. Day hospitals and respite beds, which form the backbone of support to community care in progressive geriatric and psychogeriatric services, are in danger of following in their wake.

Those of us who work in such services and are aware of clients' needs are marginalised in the new planning process by our presumed vested interest as providers. Unencumbered by our experience and concern, the new joint commissioning teams succumb to the top down imperative to redefine (by virtue of its element of social care) as much as possible of the service provided for chronic illnesses such as dementia as being outside the scope of the NHS and therefore subject to means testing and tendering to the private sector. The insensitivity of health gain and outcome measures in conditions such as dementia compounds our difficulty in stemming this tide and the resulting fragmentation of the network of specialist support and training. Unlike the commissioning teams, we witness the cost and stress to clients and carers, especially those in Challis and Henwood's category of "relatively poor" (the main victims of the changes in value added tax too).
Hills has emphasised the important functions of welfare in redistributing personal income across lifetime and insuring against risks to personal and family security, such as chronic disability. ${ }^{4}$ This is undermined by the current political delusion that our society (with its widening social inequalities and aging population) can afford to reduce direct taxation. One result is privatisation and cuts by stealth at this already underresourced margin of the NHS, with which managers in the health and social services seem forced to collude.

COLIN GODBER Consultant in old age psychiatry

Moorgreen Hospital,

Southampton SO3 3JB

1 Challis L, Henwood M. Equity in community care. $B M 9$ 1994;308:1496-9. (4 June.)

2 Godber C. Private rest homes: answers needed. BMF 1984;288: 1473-4.

3 Godber C. A happier old age in Denmark. BMF 1982;284: 1729-30.

4 Hills J. The future of welfare. York: Joseph Rowntree Foundation, 1993.

\section{Early management of myocardial infarction}

EDITOR,-We appreciate the interest shown in our article on the treatment of suspected myocardial infarction in the community.' Alastair D Short and Barbara West report that only $20 \%$ of general practitioners gave aspirin to patients suspected of having a myocardial infarction. ${ }^{2}$ This is higher than the figures reported in our study. We do not believe that our results can be explained by the fact that we depended on the recollection of the patients, who were unwell, as we also used information provided by the general practitioners both in telephone calls and in referral letters. We agree that the results of these audit studies are likely to lead to a substantial increase in the use of aspirin for patients with suspected myocardial infarction.

Most of the correspondence about our paper focused on the use of aspirin, but we wish to emphasise the other important finding of our study-namely, pain relief and the benefits of the intravenous route for administering analgesics to patients with suspected myocardial infarction.

H R WYLLIE

Senior house officer FG DUNN

Cardiac Department Consultant cardiologist

Stobhill NHS Trust,

Glasgow G22 3UW

1 Wyllie H, Dunn F. Pre-hospital opiate and aspirin adminisration in patients with suspected myocardial infarction. $B M$ 1994;308:760-1. (19 March.)

2 Short $A D$, West $B$. Early management of myocardial infarction. BMf 1994;308:1159. (30 April.)

\section{Health and safety at work}

EDITOR,-We share many of the concerns expressed by Andrew Watterson with regard to the dual threats of deregulation and underfunding of the Health and Safety Executive.' Although Britain has made important strides in health and safety in the workplace-for example, in the control of substances hazardous to health ${ }^{2}$ this seems to be changing. For example, work sponsored by the Health and Safety Executive showed that the incidence of occupational respiratory sensitisation was being underestimated. ${ }^{3}$ The Health and Safety Commission circulated draft proposals in 1992 for an approved code of practice on the control of respiratory sensitisers. Members of the British Occupational Hygiene Society responded positively to this draft, hoping that its implementation would lead to an appreciable reduction in the incidence of occu- 